\title{
Sustainable project management in urban development projects: a case study of the Greater Port Harcourt City Development Project in Rivers State, Nigeria
}

\author{
M. W. Jack, A. M. Coles \& A. Piterou \\ Department of Systems Management and Strategy, \\ University of Greenwich, UK
}

\begin{abstract}
Sustainable urban development is fundamental to future generations as it determines the longevity of a city. The strategy is about developing an urban area that fulfils the needs of the present generation, protect and preserve the environment for the future generations. Uncontrolled and unregulated urban developments in Nigeria are documented to be some of the major challenges that support unsustainable urban development. Thus, urban decay is stirred by overstretch on existing infrastructures as a result to unprecedented population growth, lack of maintenance due to institutional breakdowns, unauthorised/ unregulated construction works, and nonchalant behaviours on the part of the citizens. Sustainable urban development is a convoluted phenomenon that is dependent on several other intricate developmental strategies centric on land/water use, housing, transport, water management, waste management, sanitation, education, healthcare, and energy. These are major developmental aspects of an urban area that can drive sustainable development goals, hence, it is important to critically address the challenges that emanates as a result to the inefficiency around them. As a means to address the challenges of unsustainable urban development, this research is aimed at developing a sustainability framework for the ongoing urban development projects in Port Harcourt, Rivers State, Nigeria. To achieve the aforementioned aim, the objectives are to identify and examine the factors that are hindering the success of the project. The framework will be developed to cover major areas of stakeholders' concern. Stakeholders opinions were obtained through the collection of qualitative
\end{abstract}


primary data; face to face interviews with 52 stakeholders, non-participant observations of project sites and analysis of project documents. The data set was analysed using thematic analysis. The study revealed that political instability, lack of communication and consultation, nepotism by political officials, lack of standardised project design, lack and failure to adhere to project management regulations, and lack of continuity in government are some of the factors inhibiting the sustainability of the project.

Keywords: urbanisation, urban decay, sustainable development, sustainable urban development, infrastructure, project management, innovation, technology.

\section{Introduction}

This paper provides an insight on the determinants of sustainable urban development. The study was focused on identifying the factors inhibiting sustainable urban development in an emerging economy city, Port Harcourt, Rivers State, Nigeria. After the 1987 Brundtland Report, sustainable development became a worldwide concern amongst the international community. The campaign about climate change has significantly drawn attention to other areas of concerns, including the conditions of urban areas and cities. Most cities in emerging economies are in a dreadful condition as a result of excessive pressure on existing infrastructures like housing, road, water and energy. The influx of people into cities like Port Harcourt has drastically impacted the capacity of infrastructures, thus, several developmental strategies. These strategies are geared towards combating environmental degradation and improve the standard of urban living.

Urban development is driven by population growth; therefore, we cannot be talking about achieving sustainable development without understanding the mechanism of the population growth in urban areas. Increase in industrial and economic activities are major factors that have spurred an upshot in the number of people migrating to urban areas. Such high level of migration fuel high demand for basic amenities, thus, natural, social, human, financial and manufactured capitals are being used up. It is an established fact the intensive use of the earths' finite resources is unsustainable practices that are often seen as the major drivers of environmental degradation and climate change. Conversely, such destructive human activities have direct impact on the socio-economic life of the residents. Port Harcourt in Rivers State, Nigeria is amongst other emerging economies cities that are expressing massive degradation as a result to the gap in infrastructural development, whilst trying to cope with the growing population, there have been several urban development projects that do not fit with sustainable development initiatives. The on-going urban development project in Port Harcourt is embedded on several unsustainable practices, which that are significantly polluting the environment and increasing the concentration of the atmosphere (Link et al. [1]).

Urban areas should, therefore, be the first point of concern when trying to mitigate against the challenges of climate change. The configuration of urban areas plays a vital role on how sustainable a city is. Unprecedented population 
growth in urban areas is a major challenge, although, it is often seen as an opportunity, the long term effect on infrastructure are damaging. It is often associated with multifaceted challenges like urban decay, urban poverty, urban illiteracy, urban crime etc. Nevertheless, in order to achieve sustainable development, the root cause of such challenges needs to be understood before it can be addressed. Therefore, it is important to ask, what exactly are the determining factors of such migration? What measures can be taken to mitigate these challenges such mass migration have existing infrastructure and what can be done to improve the standard of urban living?

\section{Literature review}

This paper is based on an empirical study of urban infrastructural development gap in an emerging economy. After several years of studies and debates on the emergence of slums in urban areas, the numerous challenges they pose to the three dimensions of sustainability (social, economic and environment), and the adoption of different strategies to ensure that urban areas in developing countries are sustainable. This paper finally, identifies the factors that are inhibiting sustainable urban development from a multi-level stakeholders' perspective.

According to Gago-Cortes and Novo-Corti [2], industrialisation, globalisation, modernisation and urbanisation are concepts that fuelled unprecedented population growth, which has immensely increased the pressure on soft and hard infrastructural developments (Royuela [3]). Urbanisation is closely related with the level of economic growth (Siwar and Kasim [4]), driven by several variables that are embedded in the aforementioned concepts. Economic growth and development are directly linked to population growth, innovation, and technological advancement. According to Weiskel and Gray [5] industrialisation stimulated significant transformation in both soft and hard infrastructural developments and created fundamental change in how we work, live and think. The quest to improve the quality of life spurred migration that begot urban decay.

Urban decay is an epidemic that sweeps across several unplanned and unregulated urban areas, especially in emerging economies. It is the aftermath of a growing society without substantial plan for institutional, innovation and technological advancement. Thus, Siwar and Kasim [4] proposes that to improve the quality of urban life, particular attention should be paid to the challenges of urban areas; high density, lack of decent housing, traffic congestion, lack of energy/ water supply, lack of security, poor sanitation, poor health services, food scarcity, urban illiteracy etc. According to Silvius et al. [6], sustainability challenges are of very concrete nature. Urban areas are rapidly developing to meet the demand of the growing population; therefore, the overlapping challenges are increasing. Ford [7] posits that conventional urban developments have failed, thus, sustainable urban development is the way forward.

Sustainable urban development is a growing area of academic studies, advocating for policy intervention in strategic areas of infrastructural development. Developed countries like the United Kingdom and Germany have 
keyed into the ideology of making urban development policies and initiatives the priority of the government. Since there is no absolute solution for the challenges of urban areas, the only way will be to steer sustainable development initiatives and strategies towards the development of infrastructures like renewable energy to deliver energy efficient transport, heat and cooling; sustainable construction to deliver sustainable transport network and housing; sustainable business management to inculcate technology and innovation into the entire supply chain.

Evidently, rural-urban migration is driven by both pull and push factors (Bilham-Boult et al. [8]). Push factors are dreadful conditions that make people want to leave their dwelling places in search for better life, they are categorised as lack of soft and hard infrastructure. These drivers are largely fostered by violence, social conflict, and natural catastrophes. Pull factors are opportunities that encourage people to move to a new city or country, they are enticed by the availability of soft and hard infrastructural developments that can improve the quality of their lives.

The complexity that exists in an urban development project cannot be ignored as it involves other complicated aspects of urban living. Strzelecka [9] added that the conventional urban development has failed. Urban development has evolved from the conventional approach of providing basic infrastructures, to a more integrated approach; embedding sustainability principles into the development processes of urban areas. This approach adopts cutting-edge technologies, innovation, policies that are geared toward environmental conservation and protection, to reduce carbon footprint and improve the quality of life through supportive community programmes. Urban areas require policies that emphasise not only on economic growth but on balancing the triple bottom line of sustainability (people, profit, and the planet). To drive physical developments toward improving transportation, housing, energy, water, waste management, education healthcare, information technology and commerce.

Li [10] maintained that sustainable urban development is a key window through which the structure of urban governance is examined and reorganised. Urban infrastructures, especially housing, public transport, road networks, healthcare, agriculture, and energy are expected to expand along with the growing population in order to meet up with extreme demands. According to Agyekum-Mensah et al. [11], sustainable development is a strategy used to appropriately manage physical, natural and human assets through urban development projects. In such a time of climate change, urban areas do not only need new infrastructures but sustainable infrastructures that are driven by innovation and cutting-edge technologies to deliver efficient and effective good and services in renewable natural resources, carbon free environment, recycle water, sustainable healthcare, sustainable housing, sustainable transportation, intelligent mobility, recyclable solid waste and sustainable social community living.

Nkamnebe [13] postulated that sustainable urban redevelopment is an enabler of economic growth, environmental efficacy, and social prosperity. This means sustainability as a concept is closely knitted with social and cultural values, as the concept is influenced by demographics. Sustainability is also considered to 
be an important framework that integrates social, economic and environmental values of projects (Dempsey et al. [14]). Sustainability as a concept considers the world as a holistic system that reveals threats and opportunities of projects (Hitchcock and Willard [15]). Sustainability, therefore, defines a way of life when applied to our daily activities as it spells out good and bad practices (Peterson [16]).

In agreement with Mezher [17] the greatest challenge of this century is how to set a balance between economic growth and sustainable development. Over the past decades, several approaches have been adopted in Nigeria to achieve sustainable development, however, these approaches have been centric on the top-down process of technological diffusion, which has failed in several ways. There has not been a clear definition of sustainable urban area, hence, it is interchangeably used with several other frontiers like sustainable energy, transport, housing and business.

According to $\mathrm{Li}$ [10] sustainable urban development is a strategy towards achieving sustainable development, especially in decaying urban areas. The amount of slums building up in African cities is alarming; therefore, sustainable urban development as a strategy can be used to gradually reduce the impact of several unsustainable practices. Sustainable urban development is an opportunity for developing countries to attain the sustainable development and improve the quality of life in urban areas.

To achieve the goal of attaining uniform sustainability in urban areas, several objectives have to be met; one of such objective is to integrate sustainability principles into the project management processes of developing countries. Project management plays a vital role in how urban areas are being developed, nevertheless, the opportunity of the deisciple to stand at the forefront of sustainability have not been explored. Project management firms and other associated practitioners need to develop an innovative mindset that advocates sustainability, which will enable them to operate within the green paradigm (Rangwala [18]).

The green paradigm is increasingly becoming a more feasible region for developed countries because of several best practices instilled in their project management processes. Sustainable urban initiatives advocate considerate practices including the use of renewable materials in building infrastructures, which hugely mitigates resource depletion. The green paradigm advocated a balanced scale of the ecosystem, thereby, creating an enabling environment for peaceful coexistence.

Drawing inferences from other social science studies, stakeholders are likely to conform to ideas that are explicit to them. For instance, making people know the consequences of consuming natural capital, informative programmes on how it can damage the environment and the further health damage. Education and information sharing is an important tool in achieving sustainable development. Creating awareness about different initiatives that can be used by developing countries to muddle through unsustainable practices is and effective way to combat climate change and environmental degradation. 
Sustainable urban development projects are complex in nature, thus, they need to be modelled appropriately. Robust feasibility studies are required to establish the workability and adaptability of the design. It is inappropriate to design an urban development without the input of stakeholders. If possible, there should be advanced modelling and simulation to allow stakeholders plug in their ideas and test the viability, bearability, equitability and suitability of the project. (Capdevila and Zarlenga [19]) makes clear that an environmentally sustainable city is one that accounts for zero pollution and waste, emits zero carbon from fossil fuel and conserves its natural habitats. According to Chan and Siu [20], the concepts of sustainable urban development emerged to guide policy makers solve social problems. As emphasised by Galpin et al. [21] social support has great influence in breaking social norms and it encourages social cohesion. The following sections will address the research methodology.

\section{Research methodology}

Earlier studies on urban development identified qualitative research methods such as interviews, observation and document analysis as the most appropriate methods of enquire. According to Gummesson [22] qualitative research is a powerful tool in conducting a research that involves social actors. Qualitative research methods were employed to identify factors underpinning sustainable urban development in Port Harcourt, Rivers State, Nigeria. Speziale and Carpenter [23] maintain that qualitative research offers the researcher an opportunity to focus on finding answers to questions that emanates from a socially constructed environment, and provides an avenue for the answers to be interpreted in a way that it gives meaning to human life.

Yin [24] case studies are the most effective strategies to get an in-depth understanding of a phenomenon. The challenges established from the case study enabled the researcher to develop interview questions that were used. The interview questions consisted of ten questions; covering general participants' knowledge of the concept of sustainable development, how they perceive the going project and what they think can be done differently to achieve a sustainable urban development. A snowballing technique was used to get the participants of the three stakeholders group, which was sufficient to generalise the population (Yin [24]).

Face-to-face interviews were conducted in November 2015 with 52 interviewees, covering key stakeholders; project sponsors, project practitioners, and host community members/leaders. As confirmed by Gray [25] qualitative research methods are very effective, the participants were very interactive and open to express their opinions. The responses to interview questions emerged with unique themes and patterns that formed the basis of the data analysis.

\section{Analysis and discussion}

Thematic analysis was used to group the themes that emerged from the data set. The interview recordings emerged with strong themes that revealed a rich 
context of information about the factors underpinning the sustainable urban development of the case study project.

Respondents repeatedly mentioned that political instability is one of the factors that are hindering the success of achieving sustainable development in Port Harcourt. They further highlighted that "an unstable government cannot achieve anything tangible, no matter how much the government tries". This was as anticipated because it is a known fact around the world, political instability impedes development in any country, and it is synonymous with stagnancy in economic growth.

Respondents also pointed out that lack of continuity in government creates further instability, especially in the way institutions are managed. Some participants said, "four years is not enough to initiate and carry out such transformational projects, hence, there have to be a law that will enforce continuity". Another participant said, "every governor wants to put a signature on his achievements in government (start and finish a project in order to take the glory), therefore, when a new government comes into power, they change the working plan of the past administration and in some cases they stop the project". These comments confirmed what was observed during the observation period. The researcher observed a number of changes on the original master plan of the Greater Port Harcourt City Development Project as against what seen during the project site visits and there were a lot of abandoned project in the city. During the field work, it was also, revealed that some of the major projects have been altered as against what is on the master plan.

Centralisation of power in politically elected officials was another theme that constantly emerged. Participants commented that all government parastatal in the state are headed by politicians, which they related to being responsible for the chain reaction of failure. Some participants opined strongly that an independent civil service will move the state forward. Participant were of the view that "there are directors and permanent secretaries in the different ministries, however, they are unable to work effectively because they are headed by politically pointed commissioners, who have vested interest".

Nepotism and corruption are common themes that also emerged from the interview sessions. Participants were of the opinion that some of the projects were not viable, they were political oriented, awarded to empower a certain group of people in the community. Different participants said, "often, the people who they award development contracts to do not even start the project, they abscond with the money and nobody can do anything about it".

Lack of communication between government and project host community members was another reoccurring statement; the theme was the most popular. Participants said, "they were not consulted, hence, they know nothing about the project". Several stakeholders' studies have shown that stakeholders are bound to react impulsively, when they feel neglected. Sustainability in project management imposes a high level of responsibility on project managers, to ensure that stakeholders' requirement/need analyses are conducted effectively. Such approach to project creates inclusiveness for every stakeholder; ensuring that the social, economic and environmental concerns of the people are 
collectively taken into considered. It enables a feasibility study that takes stakeholders' views, opinions and concerns into consideration, and actively engages them through the lifespan of the project.

Lack of awareness about what sustainable development is and what indicators to look out for in a project: A major factor that underpins unsustainable development is that people lack knowledge about sustainable development and they do not understand what the initiative portrays. Policy maker's initiates and makes policies that citizens do not understand. The most effective approach to developing an urban area is to give the citizens the powers and tools they require to drive growth within their immediate environment. Creating awareness about sustainable development and what indicators to look out for in a going project is the most successful way to engage stakeholders and make them support sustainable development initiatives. As some of the participant rightly said, "if they tell us what they want to do in our communities, we will support them, knowing that the project will benefit us in terms of creating jobs for our youths and improve the standard of living in our communities".

Inappropriate land/water use/land grabbing, most respondents lamented over the land takeover by the government. They said, "the government took over their lands without compensating them appropriately; stating that they were paid N300,000 (three hundred thousand naira) compensation and the government sold the land to private buyers for N10,000,000 (ten million naira)". Other respondents from farming communities complained that "our livelihood have been taken away from us, our farmlands are designated to build different structures and we can no longer engage in commercial farming". Some respondents strongly opined that the project assigned to their communities have done no good to them, rather it has attracted crime to their local communities, their youths have resulted to crime as a result to unemployment, they experience different health challenges due to pollutions. Similarly, others complained that abandoned projects in their neigbourhood have turned breeding ground for criminals and have greatly defaced the beauty of the city.

Non adherence standardised professional codes of practice. The study revealed that, there are no standardised codes of practice for companies associated to urban development projects. Hence, they were not adhering to any regulation, which explains how projects are being initiated and executed without any form of best practices to benchmark. Again, urban developers work under the influences of political officials; hence, it becomes difficult to hold anyone responsible when there are wrong doings.

Lack of private and public investment, the study revealed that private and public investors were wary of investing in a city. They said, "the insecurity in the city have affected both social and economic growth". This was further highlighted by some participants; who revealed that investors are not willing to come invest in the city "because the city has integrated into most local communities and insecurity has become norm. Even the foreign companies that were there have packed up because of kidnappers".

Lack of enabling technologies, the study revealed that there are no new technologies in place. This is a major limitation, construction works are 
manually carried out, people work under dreadful conditions doing unhealthy manual labour, without protective clothes and tools. This relates to another important theme that emerged, energy. Nigeria does not have the capable energy to run such cutting edge technologies. The issue with power in Nigeria is a long dragging challenge; it does not only impede development, it also, has huge negative impact on the environment due to increasing demand for alternatives sources of power (carbon emission from generators).

Weak legal system, Nigeria like most countries have three arms of government (legislative, executive and judicial), however, all three arms have been engulfed by corruption. The gross collapse of the system has encouraged politicians to overrun the system with the mind-set that they make the law, hence the can break it without facing the consequences the breakdown in law enforcement. The unspeakable level of corruption in the system does not enable the law to be enforced appropriately and that has been some of the reasons for the aforementioned challenges.

All the aforementioned challenges that are inhibiting sustainable urban development, confirms that urban decay is rooted in gross institution breakdowns, and it can be combated through the implementation of sustainable development principles that are driven by effective, efficient and sustainable project management processes.

\section{Conclusion}

Industrialisation, globalisation and modernisation spurred economic growth that triggered mass rural-urban migration, which resulted to overpopulation in urban areas. The aftermath of such unprecedented population growth is urban decay, which poses overwhelming challenges in different cities. Despite, several strategies that have been employed to ensure sustainable urban infrastructural development; these strategies have been unsuccessful due to their inability to identify and address the root causes. The factors underpinning unsustainable urban development in emerging economies are numerous and mostly from different stakeholders' interference. The idebtified factors underpinning of urban decay and unsustainablity urban development are issues that can be addressed by policy makers through the implementation of a sustainable project management framework. The framework will address institution and stakeholders' concerns. There need to educate and create awareness about sustainable development to different stakeholders group; over time, developers tend to underestimate the strength of stakeholders, whilst in reality, they make and stall the development of a city. The analysis of the research clearly shows that the top-down approaches of managing infrastructural development projects are greatly opposed by stakeholders. To create synergies, stakeholders deserve to understand the benefits of the project that is being initiated on their behalf (i.e., they need to be aware of the benefits of green space, walkability, energy efficient houses, local economic growth and the strength of integrated community living). Again, there is need to empower strategic institutions and decentralised control in different government parastatals that are directly involved in urban 
infrastructural development, which can be done by investing in innovation, technology and different knowledge transfer networks. It is also, very crucial to emphasis the adherence to best practices by different urban development practitioners in order to build a level of interconnectivity required in developing a sustainable urban area.

\section{References}

[1] Link, F., Harris, J., Irarrázaval, F., Valenzuela, F., Welz, J. \& Barth, K., Coping with Natural Disasters and Urban Risk: An Approach to Urban Sustainability from Socio-Environmental Fragmentation and Urban Vulnerability Assessment, Research in Urban Sociology, 14, pp. 35-58, 2014.

[2] Gago-Corte, C. \& Novo-Corti, I., Sustainable development of urban slum areas in North Western Spain, Management of Environmental Quality: An International Journal, 26(6), pp. 891-908, 2015.

[3] Royuela, V., The role of urbanisation on international migrations: a case study of EU and ENP countries, International Journal of Manpower, Vol. 36, No. 4, pp. 469-490, 2015.

[4] Siwar, C. \& Kasim M.Y., Urban development and urban poverty in Malaysia, International Journal of Social Economics, 24(12), pp. 1524$1535,1997$.

[5] Weiskel T.C. \& Gray, R.A. (1990), He Anthropology of Environmental Decline: Part 3 Post-War Africa: A case study of underdevelopment and Ecological decline, Reference Services Review, 18(4), pp. 7-33, 1990.

[6] Silvius, G. Schipper, R. Planko, J., Brink, J.V.D. \& Kohler, A., Sustainability in Project Management, Gower Publishing Ltd. Surrey, United Kingdom, 2012.

[7] Ford, N., Crunch Time for African Cities, African Business, 49(415), pp. 16-20, 2015.

[8] Bilham-Boult A. Blades, H., Hancock, J, Ridout, M. \& Orrell. K. People, Places, and themes, $2^{\text {nd }}$ Edition, Heinemann, UK, 2001.

[9] Strzelecka, E., Urban development versus sustainable development in Poland, Management of Environmental Quality: An International Journal, 19(2), pp. 243-252, 2008.

[10] Li, Y., Sustainable Cities in Flux: Continuity, Comparisons, and Conceptions, In from Sustainable to Resilient Cities: Global Concerns and Urban Efforts, pp. 7-31, 2014.

[11] Agyekum-Mensah, G., Knight, A. \& Coffey, C., 4E's and 4 Poles model of sustainability: Redefining sustainability in the built environment, Structural Survey, 30(5), pp. 425-442, 2012.

[12] Shen, Q., Wang, H. \& Tang, B., A decision-making framework for sustainable land use in Hong Kong's urban renewal projects, Smart, and Sustainable Built Environment, 3(1), pp. 35-53, 2014. 
[13] Nkamnebe, A.D., Sustainability marketing in the emerging markets: imperatives, challenges, and agenda setting, International Journal of Emerging Markets, 6(3), pp. 217-232, 2011.

[14] Dempsey, N., Brown, C. \& Bramley, G., The Key to Sustainable Urban Development in UK Cities? The influence of density on social sustainability, Progress in Planning, 77(3), pp. 89-141, 2012.

[15] Hitchcock, D., \& Willard, M., The business guide to Sustainability: Practical strategies and Tools for Organisations, 2nd Edition, Earth scan, UK and USA, 2009.

[16] Peterson, A. Everyday Ethics, and Social Change: The Education of Desire, Columbia University Press, New York, 2009.

[17] Mezher, T., Building future sustainable cities: the need for a new mindset, Construction Innovation, 11(2), pp. 136-141, 2011.

[18] Rangwala, K., A green Paradigm, Economic Development Journal, 7(3), pp. 27-32, 2008.

[19] Capdevila, I. \& Zarlenga, M.I., Smart city or smart citizens? The Barcelona case, Journal of Strategy and Management, 8(3), pp. 266-282, 2015.

[20] Chan, K.S. \& Siu, Y.F.P. Urban governance and social sustainability, Asian Education and Development Studies, 4(3), pp. 330-342, 2015.

[21] Galpin, T., Whittington, J.L. \& Bell, G., Is your sustainability strategy sustainable? Creating a culture of sustainability, Corporate Governance, 15(1), pp. 1-17, 2015.

[22] Gummesson, E., Qualitative Methods in Management Research, 2nd Edition, Sage, London, 2000.

[23] Speziale, H.J.S. \& Carpenter, D.R., Qualitative Research in Nursing: Advancing the Humanistic Imperative, 3rd Edition, Lippincott Williams and Wilkins, Philadelphia, 2003.

[24] Yin, R.K., Case study research: Design and methods, 5th Edition, Newbury Park, CA: Sage Publications, UK, 2013.

[25] Gray, D.E., Doing Research in the Real World, Sage, London, 2014. 